\title{
ESTUDO SOBRE ELASTICIDADE E PLASTICIDADE DOS PARAFUSOS DE CABEÇOTES AUTOMOTIVOS
}

\section{ARTIGO ORIGINAL}

PINHEIRO, Samuel Junio França ${ }^{1}$

PINHEIRO, Samuel Junio França. Estudo sobre elasticidade e plasticidade dos parafusos de cabeçotes automotivos. Revista Científica Multidisciplinar Núcleo do Conhecimento. Ano 05, Ed. 06, Vol. 02, pp. 149-169. Junho de 2020. ISSN: 24480959, Link de acesso: https://www.nucleodoconhecimento.com.br/engenhariamecanica/elasticidade-e-plasticidade

\section{RESUMO}

Os parafusos devem manter as forças de aperto aplicadas, no entanto, após o torque e o ciclo de carga, ocorre um alongamento em sua estrutura. A eficiência de tal componente é vital para o perfeito ajuste e funcionamento do motor. Nesse trabalho, propõe-se um comparativo entre as deformações reais e as obtidas a partir da simulação computacional dos parafusos de cabeçote, retirados de motores a gasolina e a diesel. Os parafusos usados no experimento serão de cabeçotes de veículos de passeio e utilitário de quatro diferentes marcas: Pálio 1.6 16v, Marea 2.0, Zafira $2.0 \mathrm{e}$ Pajero 2.8 Diesel.

Palavras-chave: Parafusos, tração, deformação, cálculos, cabeçote.

\section{INTRODUÇÃO}

O grego Archytas de Tarentum foi o responsável pelo desenvolvimento do parafuso por volta de 400 a.C. Na época, foi desenvolvido para ser utilizado em prensas para extração de azeite de olivas, bem como na produção de vinho. A história do parafuso,

\footnotetext{
1 Técnico em Segurança do Trabalho.
} 
em suas múltiplas versões, aponta que Arquimedes, por volta de 250 a.C, desenvolveu o princípio da rosca, utilizando-a para a construção de dispositivos para o transporte de água na irrigação. O primeiro documento impresso sobre parafusos consta em um livro do começo do século XV, porém os parafusos de metal só apareceram na Europa a partir do ano de 1400 e Johann Gutenberg incluiu estes componentes entre os fixadores de sua impressora (Revista Parafuso).

Nota-se que, ao longo da história, o parafuso foi sempre solução de infindáveis problemas, e, naturalmente, gerava outros, pois eram feitos por diferentes inventores e não havia normas e padrões. Em razão dessa necessidade criou-se as padronizações, obtendo, assim, resultados que tornaram a sua aplicação universal. Segundo Norton (2011), o parafuso presente em um projeto pode parecer um de seus aspectos menos interessante, mas é, na verdade, um dos mais fascinantes. Dessa forma, milhares de diferentes projetos de juntas são oferecidos pelos vendedores, que, por sua vez, são utilizadas em montagens complexas, como de um automóvel ou avião.

\section{METODOLOGIA}

O trabalho consiste na análise estrutural de amostras de parafusos retirados em cabeçote de motores à combustão análogo ao ciclo Otto e Diesel comparando com parafusos novos e analisando a deformação sofrida após o torque exigido pelo fabricante (SILVEIRA, 2008; FERNANDEZ, 2006; ARAÚJO, 2007). De posse dos parafusos, foi definida sua composição metálica baseando-se em suas propriedades mecânicas, medições e cálculos de esforços ao quais foram submetidos, e, após isso, serão aplicados os parâmetros obtidos para simulação computacional utilizando o software SolidWorks2019. Para a realização do experimento foram utilizadas as seguintes ferramentas:

- Paquímetro;

- Software SolidWorks 2019;

- Máquina para ensaio de tração GUNT WP 300.20 TENSILE TEST; 
- Fórmula da lei de Hooke para Deformação

A Lei de Hooke foi utilizada nos cálculos para determinar a força a partir da deformação. A lei determina a deformação sofrida por um corpo elástico através de uma força (LABURU; ALMEIDA, 1998; MASCIA, 2006). A fórmula utilizada corresponde à equação 1 .

$$
\begin{gathered}
\delta=\frac{F \cdot L_{0}}{A \cdot E} \Rightarrow F=\frac{\delta \cdot A \cdot E}{L_{0}} \\
\delta=L_{f}-L_{0}
\end{gathered}
$$

Onde:

$\delta$ - alongamento da peça em [m] F - carga nominal aplicada $[\mathrm{N}]$

E - modulo de elasticidade $[\mathrm{Pa}]$ A - área da secção transversal $\left[\mathrm{m}^{2}\right]$

Lo - comprimento inicial da peça $\mathrm{L}_{f}$ - comprimento final

Foram analisados os parafusos de cabeçote dos motores referentes aos seguintes carros, conforme consta tabela 1 :

Tabela 1: Relação veículos/parafusos

Veículo Quant. Parafusos

Fiat Marea $2.0\left(1^{\circ} \mathrm{motor}\right) 2$

Fiat Marea 2.0 (2ํmotor) 12

FIAT Palio 1.6 10 
GM Zafira 2.0

MITSUBISHI Pajero 2.8

Diesel

Fonte: Autor (2020)

A fim de testar o experimento, foram feitas medições de todos os parafusos para saber o quanto o parafuso se alongou e após todas as medições terem sido feitas e anotadas, usou-se uma planilha e elaborou-se o gráfico com as comparações necessárias à compreensão acerca do o quão é importante saber a deformação do parafuso após o torque exercido. Depois fez-se uso do SolidWorks 2019 para comparar os resultados do experimento realizado.

\section{RESULTADOS E DISCUSSÃO}

Os parafusos de cabeçote para motores à combustão, em geral, possuem propriedades elásticas e de resistência bem específica. O parafuso possuí uma resistência a tração inicial e um torque fornecido pré-determinado pelo fabricante gera uma tensão normal na área da cabeça do parafuso, e, essa tensão, deve-se à "précarga inicial" (assentamento da peça) e aos passos de aperto angular subsequentes indicados por cada fabricante.

\subsection{PRÉ-CARGA}

A pré-carga é o aperto definido pelo fabricante ou montadora efetuado utilizando-se um taquímetro para tencionar e assentar a tampa do cabeçote (processo de baixa complexidade necessitando apenas a regulagem do taquímetro e sua correta utilização) (LA CAVA et al, 2000; SCHWONBACH et al, 2008) 


\subsection{APERTO ANGULAR}

Este processo pode ser dimensionado para utilizar a capacidade máxima de resistência do parafuso, ou seja, o parafuso se deforma na região plástica sem que haja a falha do parafuso (COURTES et al, 2017; MONTEIRO, 2016). A composição química do parafuso de cabeçote possuí alta "ductibilidade" (capacidade de se deformar antes da falha da estrutura). A fase de ângulo do aperto é a mais precisa e seu dimensionamento é feito para que ultrapasse o escoamento em $100 \%$ dos casos, e, por esse motivo, é extraído à máxima força e menores dimensões precisam ser considerados no cálculo. A consequência disso é que esse método permite que sejam utilizados parafusos menores para se ter a força esperada e manter a junta em funcionamento, conforme assinalado por Garcia (2008).

\subsection{ANÁLISE}

A análise realizou-se por meio da comparação de parafusos novos (medidas fornecidas pelo fabricante) e parafusos usados retirado de motores após manutenção. Foram realizadas medições com paquímetro sendo 14 amostras de parafuso de cabeçote do Fiat Marea 2.0, 22 amostras da Mitsubishi Pajero 2.8D, 10 amostras do Fiat Palio 1.6 e 10 amostras da GM Zafira 2.0. Observou-se que os parafusos usados possuíam comprimento diferentes dos parafusos novos. Buscou-se, então, saber a tensão aplicada em cada parafuso para gerar as deformações observadas. Obteve o deslocamento linear de cada parafuso e os dados de deslocamento linear de cada parafuso. Para este experimento foram utilizados como base o aço 4340 para as amostras dos carros Palio, Marea e Pajero, com a elasticidade de 210GPa.

Já para o carro Zafira foi utilizado como base o aço 6150 com a elasticidade de 190GPa. Detectou-se que o aço 4340, por exemplo, tem um limite de escoamento de $460 \mathrm{MPa}$, que é o limite da sua tensão dentro da fase de deformação elástica. Caso a força aplicada ao parafuso exceda o limite de escoamento, ou seja, ultrapasse a força de 460MPa, o parafuso entra na fase de deformação plástica, não retornando mais ao seu formato original. Conforme gráfico da figura 1, o limite de escoamento do aço, ou 
seja, os 460Mpa, estão representados no "бesc.", onde termina a fase elástica e começa a fase plástica. A tensão máxima suportada pelo corpo é representada pelo " $\sigma R$ " na fase plástica e, em seguida, no ponto "V", que é o instante em que o corpo se rompe.

Figura 1: Gráfico de Tensão/ Deformação

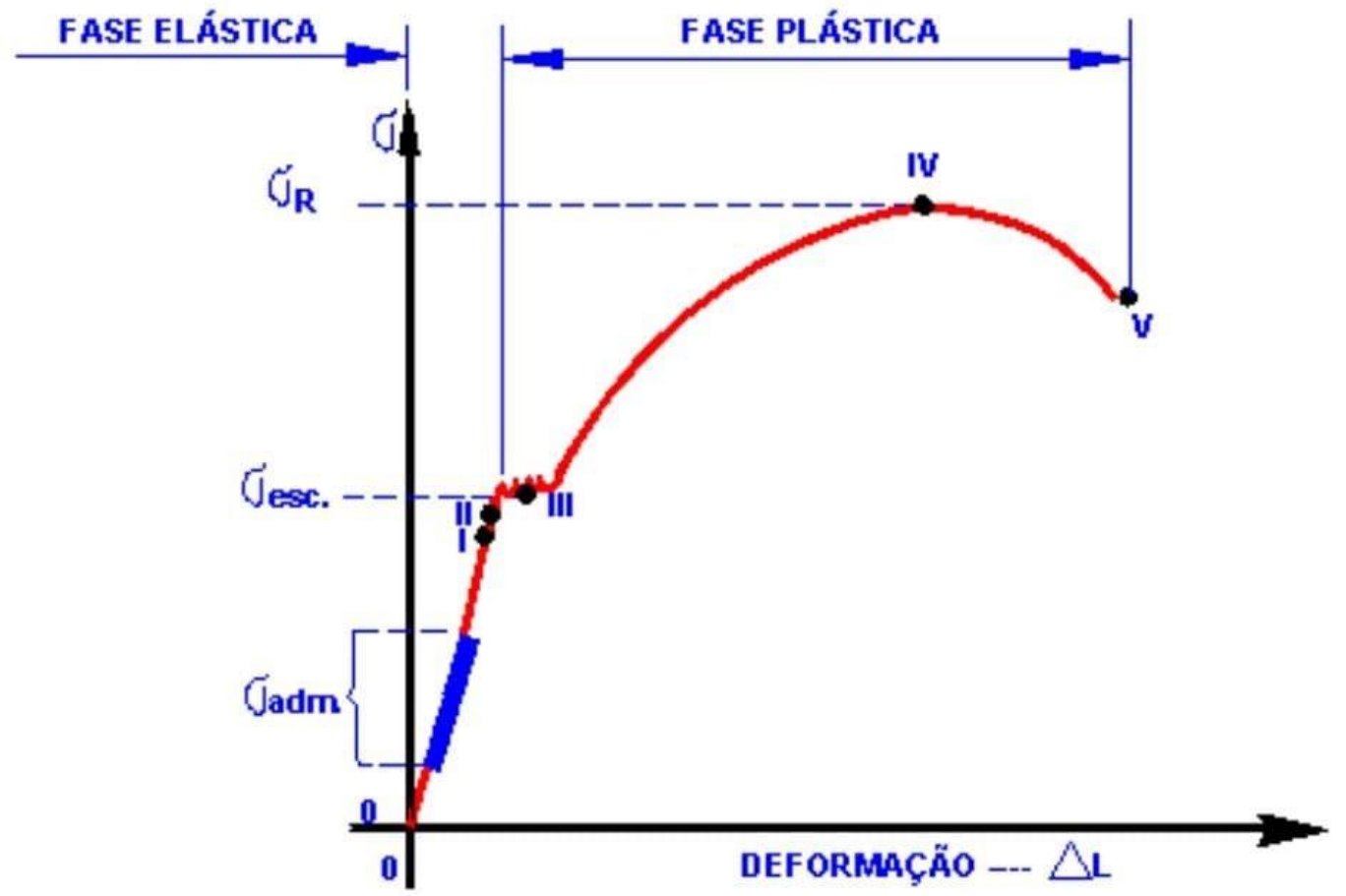

Fonte: Disponível em: http://grupomec.tripod.com/Material.htm, 11-02-2020, $20 \mathrm{~h} 11 \mathrm{~min}$

Com base nos dados colhidos e nas fórmulas utilizadas, gerou-se as seguintes planilhas comparando as tensões normais aplicadas a cada parafuso e, consequentemente, gerando o deslocamento medido nos parafusos usados:

Tabela 2: Comparativos parafusos/Marea Lote 1 e 2

\section{Parafusos de cabeçote do carro Marea 2.0 (1ํlote)}




\begin{tabular}{|c|c|c|c|}
\hline $\begin{array}{l}\text { Medida } \\
\text { Inicial } \\
(254 \mathrm{~mm})\end{array}$ & $\begin{array}{l}\text { Alongamento } \\
\text { Real (mm) }\end{array}$ & $\begin{array}{l}\text { Alongamento } \\
\text { software } 2019 \\
\text { SolidWorks }(\mathrm{mm})\end{array}$ & $\begin{array}{l}\text { Diferencial (\%) Real vs } \\
\text { SolidWorks }\end{array}$ \\
\hline P1 & 257,10 & 261,56 & $1,71 \%$ \\
\hline P2 & 256,90 & 261,07 & $1,60 \%$ \\
\hline \multicolumn{4}{|c|}{ Parafusos de cabeçote do carro Marea 2.0 (2 lote) } \\
\hline $\begin{array}{l}\text { Medida } \\
\text { Inicial } \\
(254 \mathrm{~mm})\end{array}$ & $\begin{array}{l}\text { Alongamento } \\
\text { Real (mm) }\end{array}$ & $\begin{array}{l}\text { Alongamento } \\
\text { software } 2019 \\
\text { SolidWorks (mm) }\end{array}$ & $\begin{array}{l}\text { Diferencial } \\
\text { Original/Software (\%) }\end{array}$ \\
\hline P1 & 255,50 & 257,66 & $0,84 \%$ \\
\hline $\mathbf{P} 2$ & 255,50 & 257,66 & $0,84 \%$ \\
\hline P3 & 255,15 & 256,80 & $0,64 \%$ \\
\hline P4 & 255,50 & 257,66 & $0,84 \%$ \\
\hline P5 & 255,75 & 258,27 & $0,98 \%$ \\
\hline P6 & 255,50 & 257,66 & $0,84 \%$ \\
\hline P7 & 255,05 & 256,56 & $0,59 \%$ \\
\hline P8 & 255,10 & 256,68 & $0,62 \%$ \\
\hline P9 & 255,10 & 256,68 & $0,62 \%$ \\
\hline P10 & 255,75 & 258,27 & $0,98 \%$ \\
\hline P11 & 255,50 & 257,66 & $0,84 \%$ \\
\hline P12 & 255,50 & 257,66 & $0,84 \%$ \\
\hline
\end{tabular}

Fonte: Autor (2020)

Tabela 3: Comparativos parafusos/Pajero

Parafusos de cabeçote do carro Pajero 2.8

\begin{tabular}{|l|l|l|l|} 
Medida Inicial & Alongamento & $\begin{array}{l}\text { Alongamento } \\
\text { software 2019 }\end{array}$ & Diferencial \\
\hline P1 à P4 (104mm) & Real $(\mathrm{mm})$ & $\begin{array}{l}\text { Orinal/Software (\%) } \\
\text { SolidWorks (mm) }\end{array}$ &
\end{tabular}

Disponível em: https://www.nucleodoconhecimento.com.br/engenharia-mecanica/elasticidade-eplasticidade 


\begin{tabular}{|c|c|c|c|}
\hline $\begin{array}{l}\text { P5 à P8 (125mm) } \\
\text { P9 à P22 (106mm) }\end{array}$ & & & \\
\hline P1 Cabeça Lisa & 104,80 & 104,93 & $0,12 \%$ \\
\hline P2 Cabeça Lisa & 104,71 & 104,83 & $0,11 \%$ \\
\hline P3 Cabeça Lisa & 104,65 & 104,76 & $0,11 \%$ \\
\hline P4 Cabeça Lisa & 104,85 & 104,99 & $0,13 \%$ \\
\hline P5 Cabeça Estriada & 125,55 & 126,00 & $0,36 \%$ \\
\hline P6 Cabeça Estriada & 126,35 & 127,74 & $1,09 \%$ \\
\hline P7 Cabeça Estriada & 125,95 & 126,72 & $0,61 \%$ \\
\hline P8 Cabeça Estriada & 126,10 & 127,00 & $0,71 \%$ \\
\hline P9 Cabeça Estriada & 106,10 & 106,87 & $0,72 \%$ \\
\hline $\begin{array}{ll}\text { P10 } & \text { Cabeça } \\
\text { Estriada } & \end{array}$ & 106,10 & 106,87 & $0,72 \%$ \\
\hline $\begin{array}{ll}\text { P11 } & \text { Cabeça } \\
\text { Estriada } & \end{array}$ & 106,10 & 106,87 & $0,72 \%$ \\
\hline $\begin{array}{ll}\text { P12 } & \text { Cabeça } \\
\text { Estriada } & \end{array}$ & 107,30 & 108,92 & $1,49 \%$ \\
\hline $\begin{array}{l}\text { P13 Cabeça } \\
\text { Estriada }\end{array}$ & 106,10 & 106,87 & $0,72 \%$ \\
\hline $\begin{array}{l}\text { P14 } \\
\text { Estriada }\end{array}$ & 106,90 & 108,24 & $1,24 \%$ \\
\hline $\begin{array}{l}\text { P15 } \\
\text { Estriada }\end{array}$ & 105,55 & 105,93 & $0,36 \%$ \\
\hline $\begin{array}{l}\text { P16 } \\
\text { Estriada }\end{array}$ & 105,55 & 105,93 & $0,36 \%$ \\
\hline $\begin{array}{l}\text { P17 } \\
\text { Estriada }\end{array}$ & 106,45 & 107,47 & $0,95 \%$ \\
\hline $\begin{array}{ll}\text { P18 } & \text { Cabeça } \\
\text { Estriada } & \end{array}$ & 105,90 & 106,53 & $0,59 \%$ \\
\hline
\end{tabular}

Disponível em: https://www.nucleodoconhecimento.com.br/engenharia-mecanica/elasticidade-eplasticidade 


\begin{tabular}{|ll|l|l|l|}
\hline $\begin{array}{l}\text { P19 } \\
\text { Estriada }\end{array}$ & Cabeça & 106,85 & 108,15 & $1,20 \%$ \\
\hline $\begin{array}{l}\text { P19 } \\
\text { Estriada }\end{array}$ & Cabeça & 106,10 & 106,87 & $0,72 \%$ \\
\hline $\begin{array}{l}\text { P20 } \\
\text { Estriada }\end{array}$ & Cabeça & 106,80 & 108,07 & $1,18 \%$ \\
\hline $\begin{array}{l}\text { P21 } \\
\text { Estriada }\end{array}$ & Cabeça & 106,30 & 107,21 & $0,85 \%$ \\
\hline $\begin{array}{l}\text { P22 } \\
\text { Estriada }\end{array}$ & Cabeça & 109,59 & 110,35 & $0,69 \%$ \\
\hline
\end{tabular}

Fonte: Autor (2020)

Tabela 4: Comparativos parafusos/Zafira

Parafusos de cabeçote do carro Zafira 2.0

\begin{tabular}{|l|l|l|l|}
\hline $\begin{array}{l}\text { Medida } \\
\text { Inicial } \\
\mathbf{( 1 3 6 m m )}\end{array}$ & $\begin{array}{l}\text { Alongamento } \\
\text { Real }(\mathrm{mm})\end{array}$ & $\begin{array}{l}\text { Alongamento } \\
\text { software } \\
\text { SolidWorks }(\mathrm{mm})\end{array}$ & $\begin{array}{l}\text { Diferencial } \\
\text { Original/Software (\%) }\end{array}$ \\
\hline P1 & 137,00 & 139,08 & $1,50 \%$ \\
\hline P2 & 136,90 & 138,78 & $1,35 \%$ \\
\hline P3 & 136,80 & 138,47 & $1,21 \%$ \\
\hline P4 & 136,90 & 138,78 & $1,35 \%$ \\
\hline P5 & 137,00 & 139,08 & $1,50 \%$ \\
\hline P6 & 136,90 & 138,78 & $1,35 \%$ \\
\hline P7 & 136,90 & 138,78 & $1,35 \%$ \\
\hline P8 & 136,70 & 138,16 & $1,06 \%$ \\
\hline P9 & 136,80 & 138,47 & $1,21 \%$ \\
\hline P10 & 136,80 & 138,47 & $1,21 \%$ \\
\hline
\end{tabular}

Fonte: Autor (2020)

Disponível em: https://www.nucleodoconhecimento.com.br/engenharia-mecanica/elasticidade-eplasticidade 
Tabela 5: Comparativos parafusos/Palio

\begin{tabular}{|l|l|l|l|}
\hline $\begin{array}{l}\text { Parafusos de cabeçote do carro Palio 1.6 } \\
\text { Inicial } \\
\text { 100mm }\end{array}$ & $\begin{array}{l}\text { Alongamento } \\
\text { Real }(\mathrm{mm})\end{array}$ & $\begin{array}{l}\text { Alongamento } \\
\text { software } \\
\text { SolidWorks }(\mathrm{mm})\end{array}$ & $\begin{array}{l}\text { Diferencial } \\
\text { Original/Software (\%) }\end{array}$ \\
\hline P1 & 100,99 & 101,16 & $0,17 \%$ \\
\hline P2 & 100,99 & 101,16 & $0,17 \%$ \\
\hline P3 & 100,75 & 100,87 & $0,12 \%$ \\
\hline P4 & 100,75 & 100,87 & $0,12 \%$ \\
\hline P5 & 100,99 & 101,16 & $0,17 \%$ \\
\hline P6 & 100,99 & 101,16 & $0,17 \%$ \\
\hline P7 & 101,00 & 101,17 & $0,17 \%$ \\
\hline P8 & 101,00 & 101,17 & $0,17 \%$ \\
\hline P9 & 100,99 & 101,16 & $0,17 \%$ \\
\hline P10 & 100,99 & 101,16 & $0,17 \%$ \\
\hline
\end{tabular}

Fonte: Autor (2020)

No primeiro experimento feito nos parafusos do cabeçote do carro Marea foi encontrada uma tensão média de $508 \mathrm{KPa}$ ao qual os parafusos foram solicitados durante a aplicação do torque, ocorrendo, no parafuso, o deslocamento médio de $3 \mathrm{~mm}$. No gráfico 1, tem-se as tensões do primeiro experimento.

Disponível em: https://www.nucleodoconhecimento.com.br/engenharia-mecanica/elasticidade-eplasticidade 
Gráfico 1: Parafusos de cabeçote Marea $2.0\left(1^{\circ} \mathrm{motor}\right)$

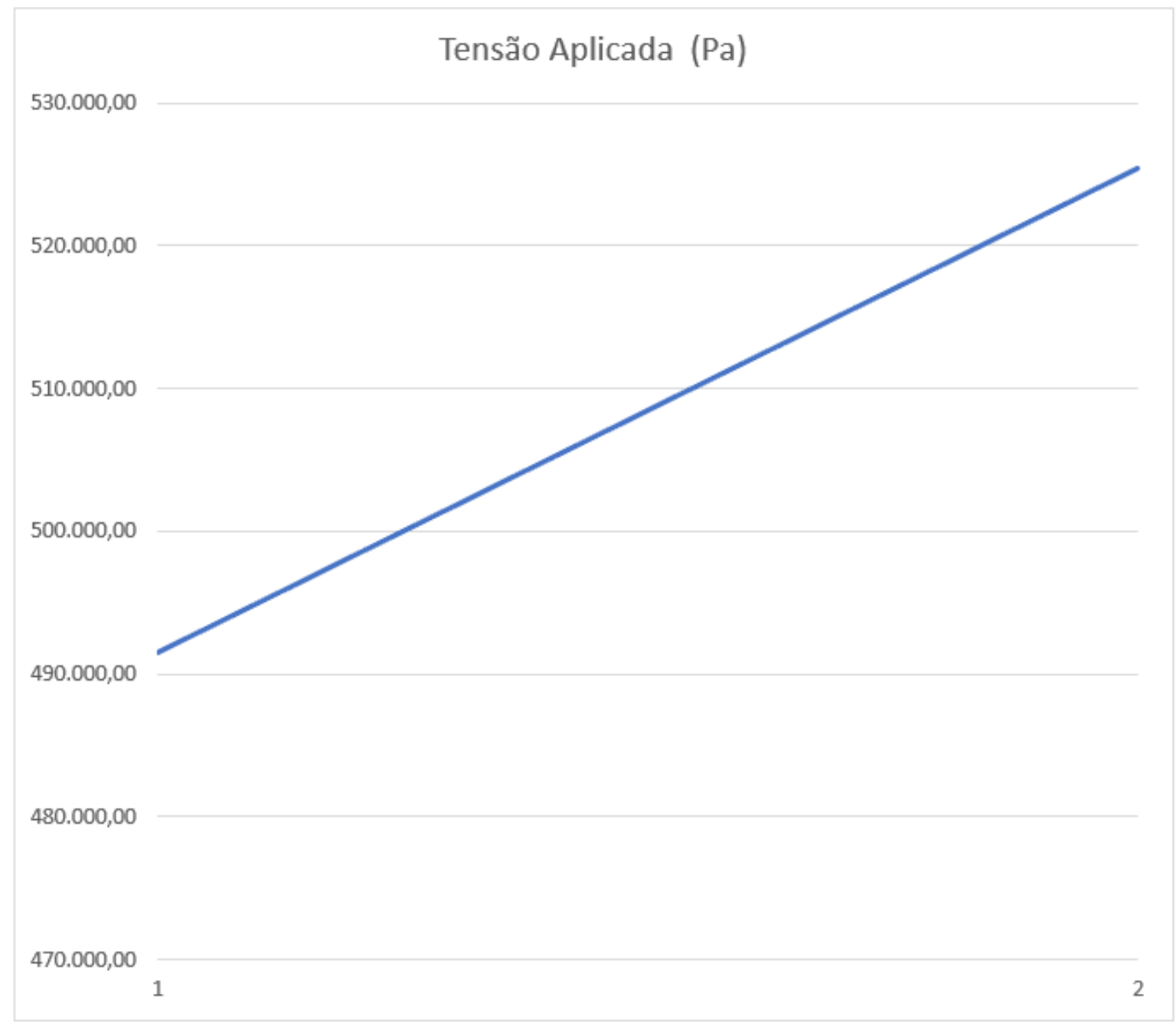

Fonte: Autor (2020)

RC: 51573

Disponível em: https://www.nucleodoconhecimento.com.br/engenharia-mecanica/elasticidade-eplasticidade 
Figura 2: Parafuso Marea Tipo 1 SolidWorks 2019

Nome do modelo:parafuso marea $2.0-1$

No me do estudo:Análise estática 4(-Valor predeterminado-)

Tipo de plotagem: Deslo camento estático Deslo camento1

Escala de distor ção: 3,47526

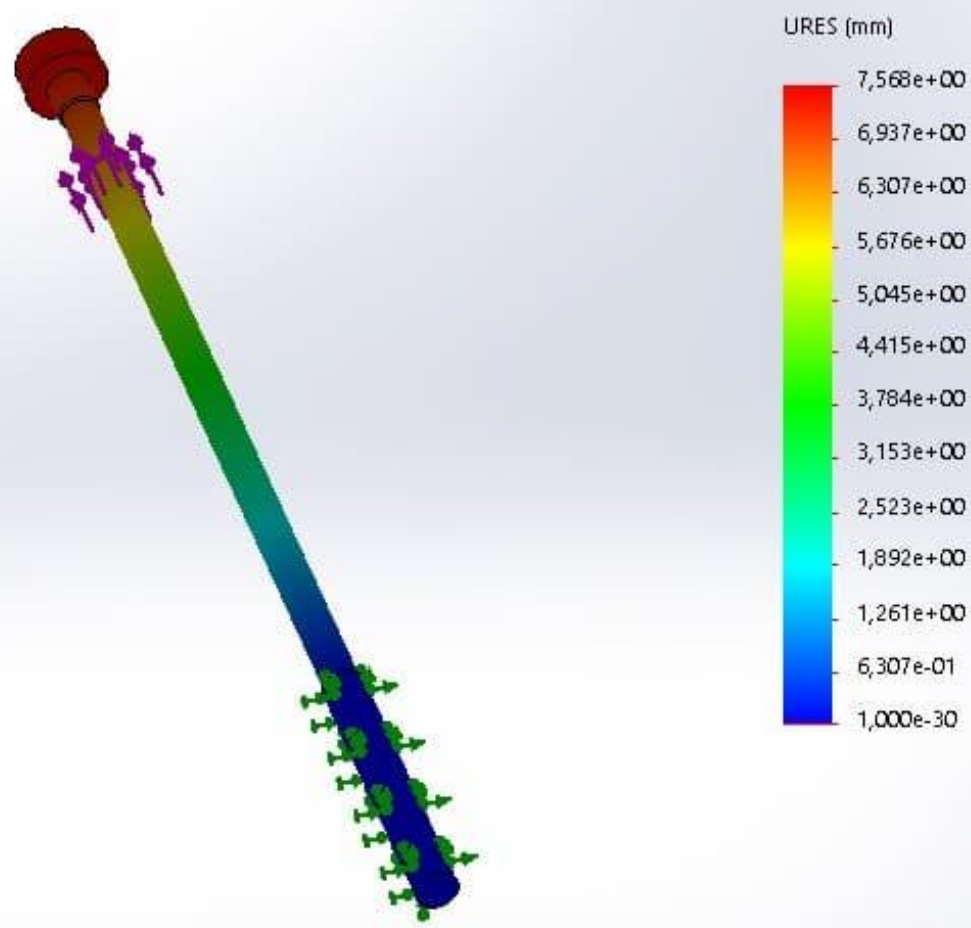

Fonte: Autor (2020)

No segundo experimento foi usado o mesmo modelo, porém a tensão encontrada foi $54,73 \%$ menor, comparada ao primeiro experimento, e, assim, a tensão média encontrada foi de $239 \mathrm{KPa}$, ao qual os parafusos foram solicitados durante a aplicação do torque e, consequentemente, ocorreu, no parafuso, o deslocamento médio de $1,41 \mathrm{~mm}$. No gráfico 2 são representadas as tensões do segundo experimento.

Disponível em: https://www.nucleodoconhecimento.com.br/engenharia-mecanica/elasticidade-eplasticidade 
Gráfico 2: Parafusos de cabeçote Marea 2.0 (2ํmotor)

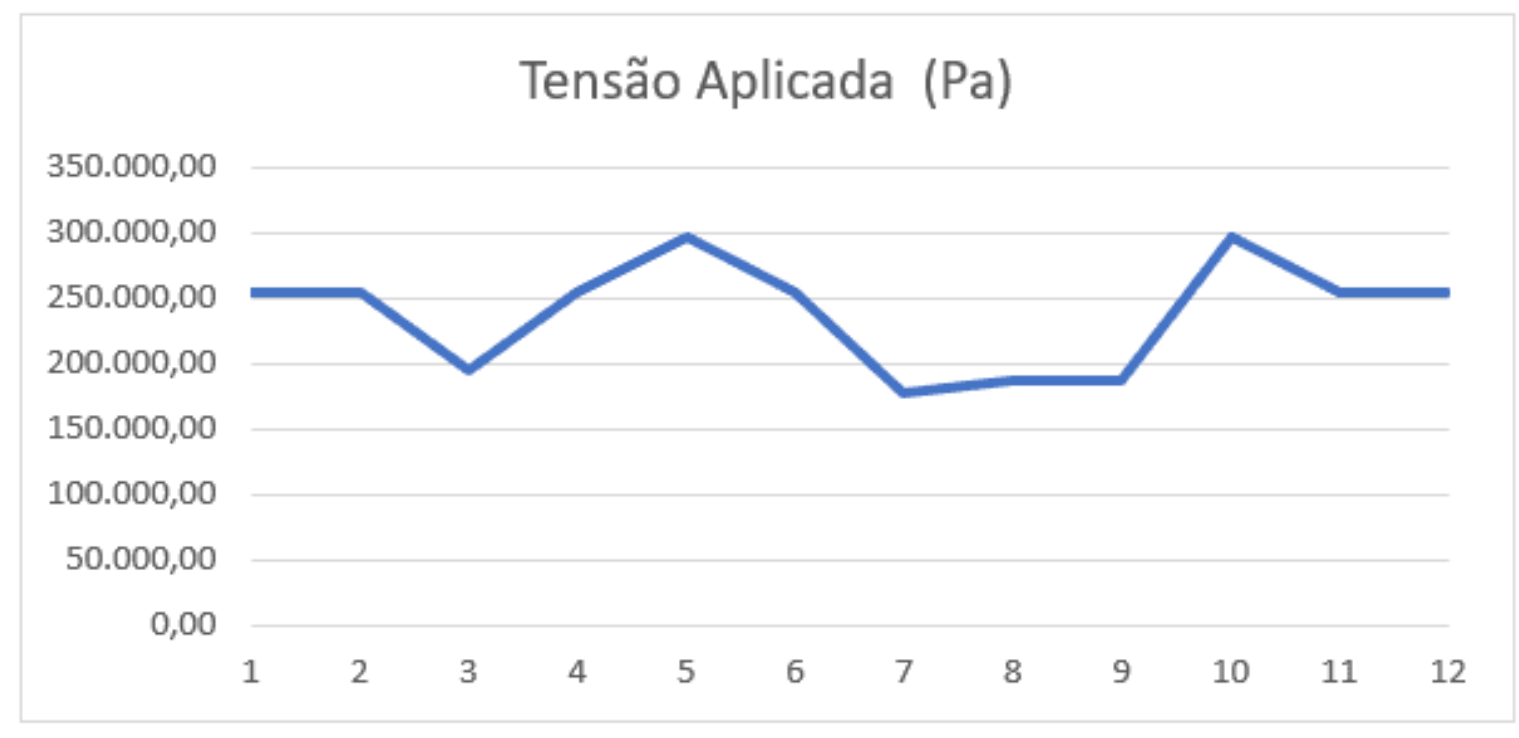

Fonte: Autor (2020)

Figura 3: Parafuso Marea Tipo 2 SolidWorks 2019

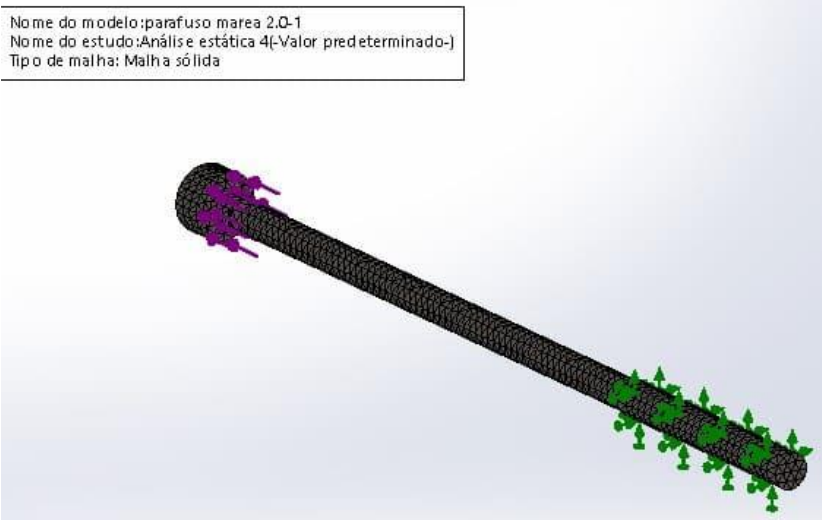

Fonte: Autor (2020)

RC: 51573

Disponível em: https://www.nucleodoconhecimento.com.br/engenharia-mecanica/elasticidade-eplasticidade 
No terceiro experimento o cabeçote utilizado foi do Pajero e nele encontrou-se 3 tipos de parafusos, e, assim, foram feitos 3 gráficos diferentes. A tensão média encontrada para o parafuso tipo 1 foi de $240 \mathrm{KPa}$, conforme mostra o gráfico 3 , sendo o deslocamento médio de $0,85 \mathrm{~mm}$.

Gráfico 3: Parafusos de cabeçote Pajero 2.8 - Tipo 1

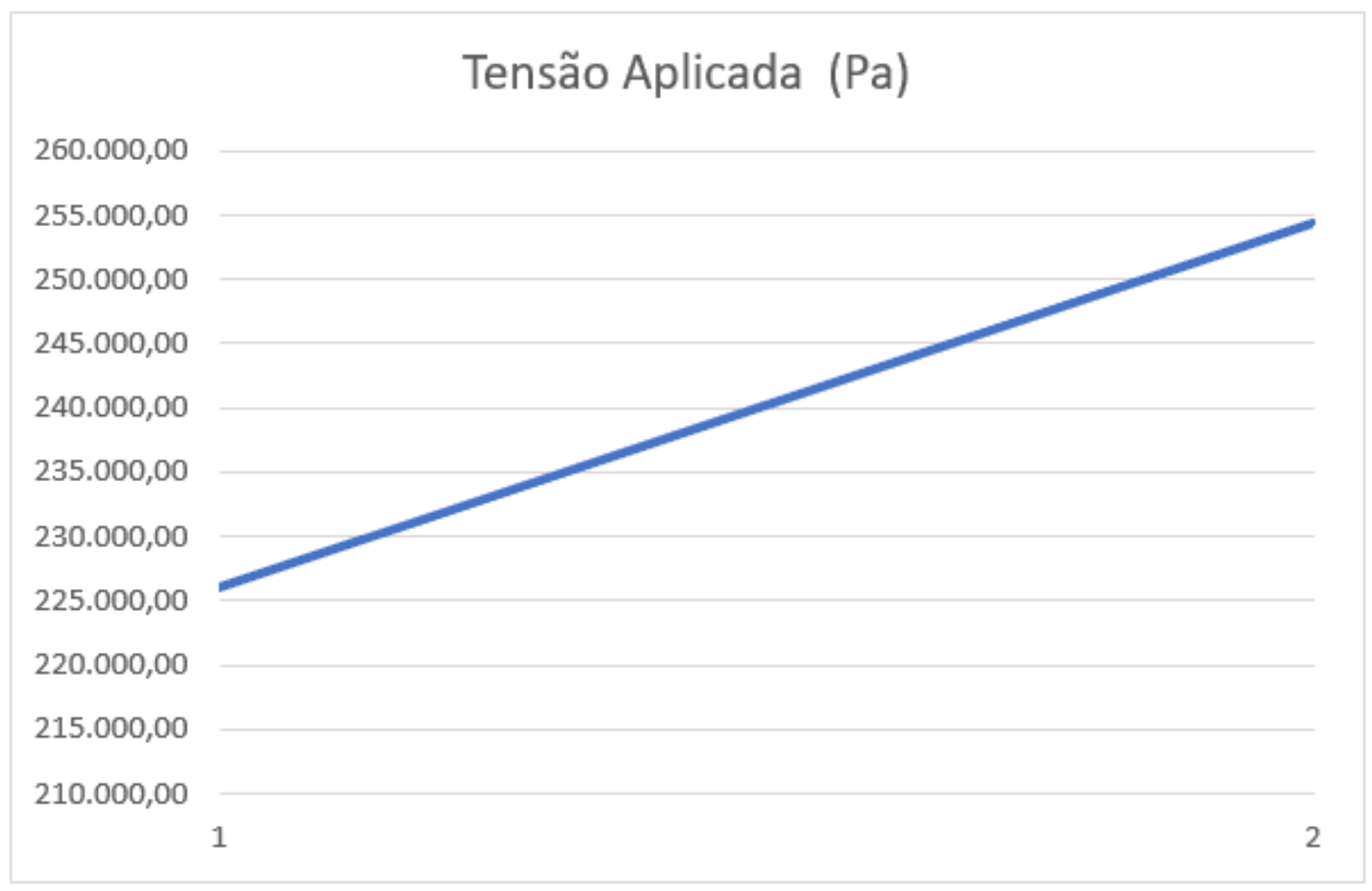

Fonte: Autor (2020)

Disponível em: https://www.nucleodoconhecimento.com.br/engenharia-mecanica/elasticidade-eplasticidade 
Figura 4: Parafuso Marea Tipo 1 SolidWorks 2019

Nome do modelo:Parafuso pajero2.8 P9 a P22

No me do estudo:Análise estática 2 (-Valor predeterminado-)

Tipo de plotagem: Análise estática tensão nodal Tensão1

Escala de distor ưăo: 11,9513

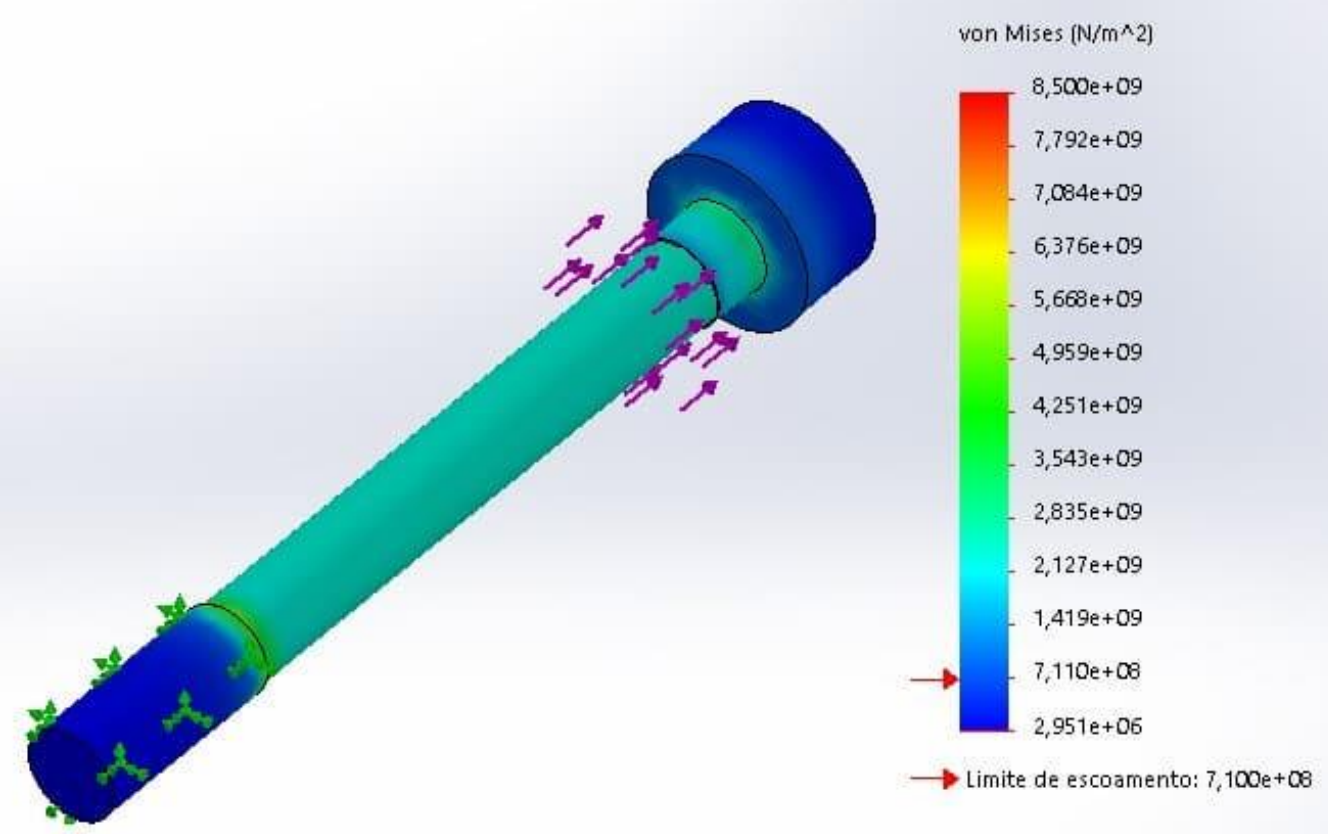

Fonte: Autor (2020)

No parafuso tipo 2 do Pajero a tensão média encontrada foi de 433KPa. Essa média se dá conforme gráfico 4 e possui um deslocamento médio de $0,99 \mathrm{~mm}$.

Disponível em: https://www.nucleodoconhecimento.com.br/engenharia-mecanica/elasticidade-eplasticidade 
Gráfico 4: Parafusos de cabeçote Pajero 2.8 - Tipo 2

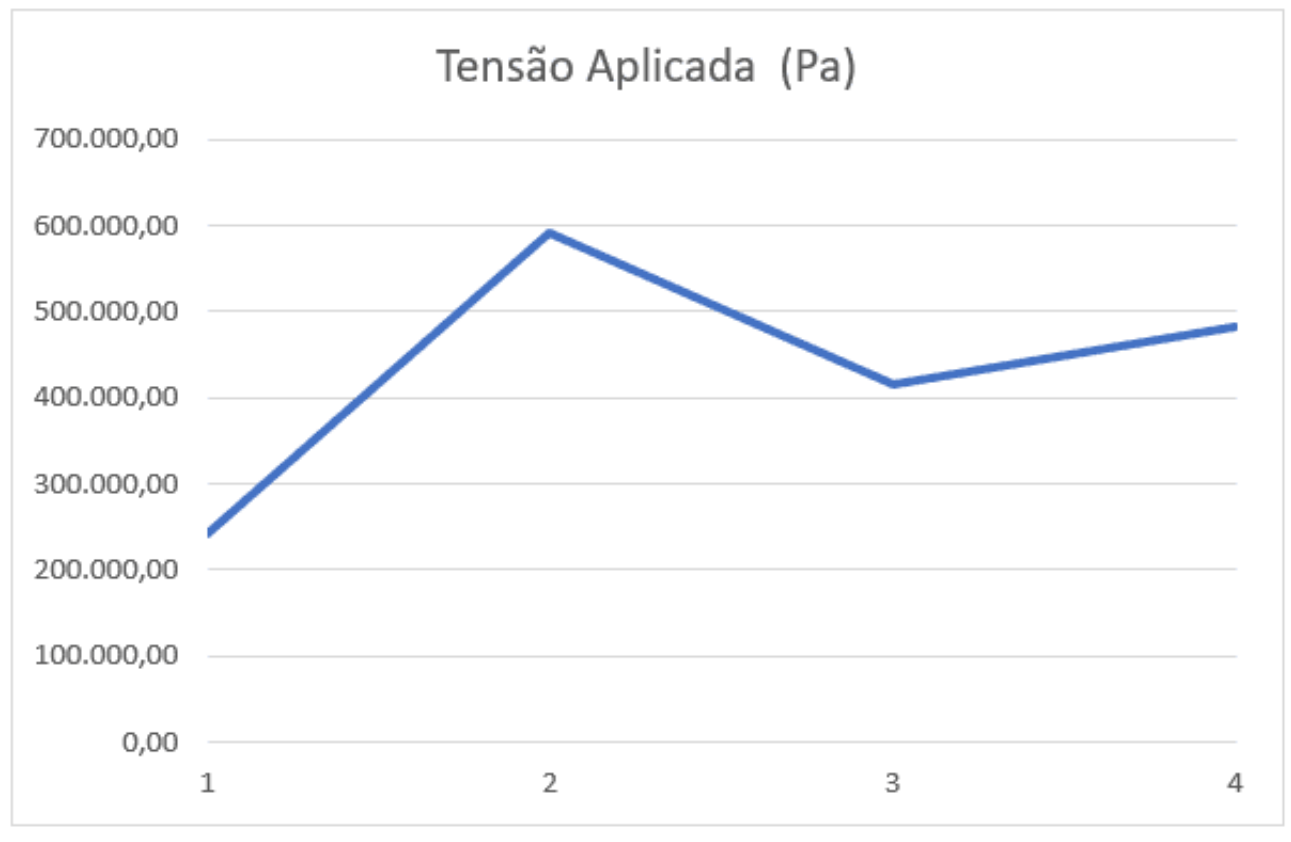

Fonte: Autor (2020)

Figura 5: Parafuso Pajero Tipo 2 - SolidWorks 2019

Nome do modelo:Parafu so pajero2.8 $\mathrm{P3}$ a P6
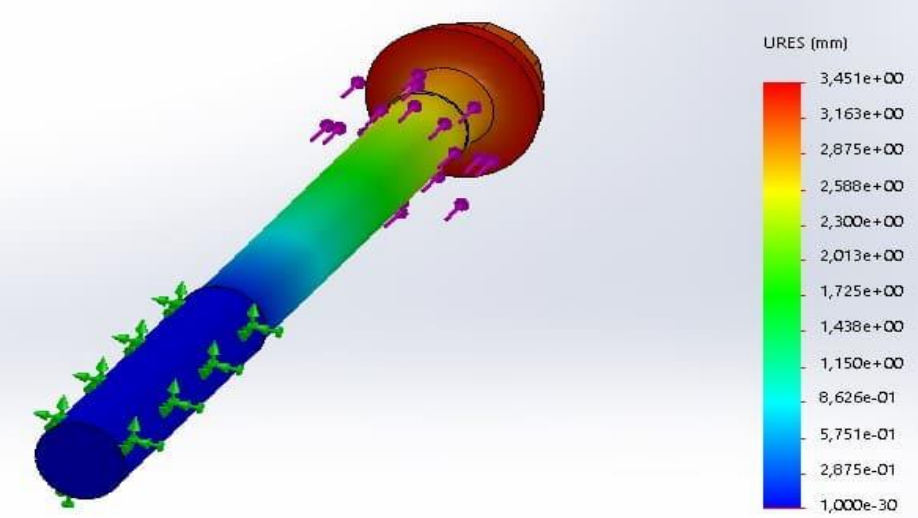

Fonte: Autor (2020)

RC: 51573

Disponível em: https://www.nucleodoconhecimento.com.br/engenharia-mecanica/elasticidade-eplasticidade 
No terceiro modelo do Pajero foi encontrada a tensão de $705 \mathrm{KPa}$, conforme mostra o gráfico 5 e, assim, obteve-se um deslocamento médio de 1,29 mm. Finalizando, dessa forma, o terceiro experimento.

Gráfico 5: Parafusos de cabeçote Pajero 2.8 - Tipo 3

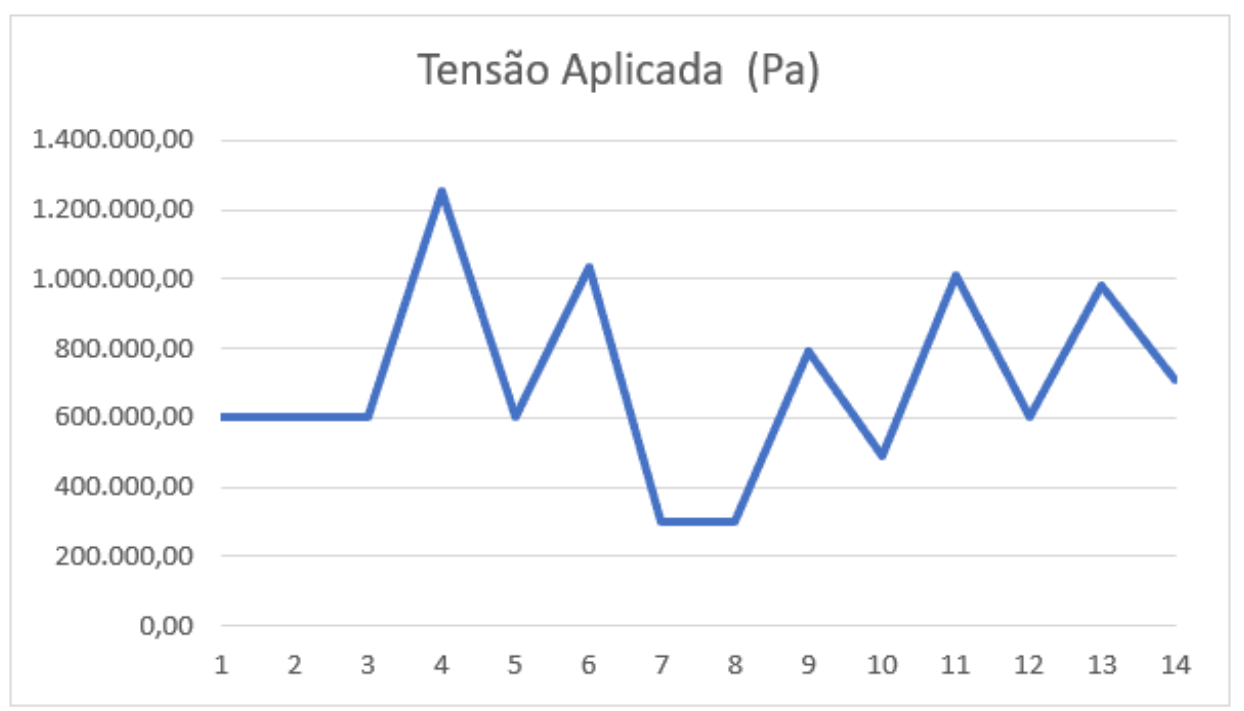

Fonte: Autor (2020)

Figura 6: Parafuso Pajero Tipo 3 - SolidWorks 2019

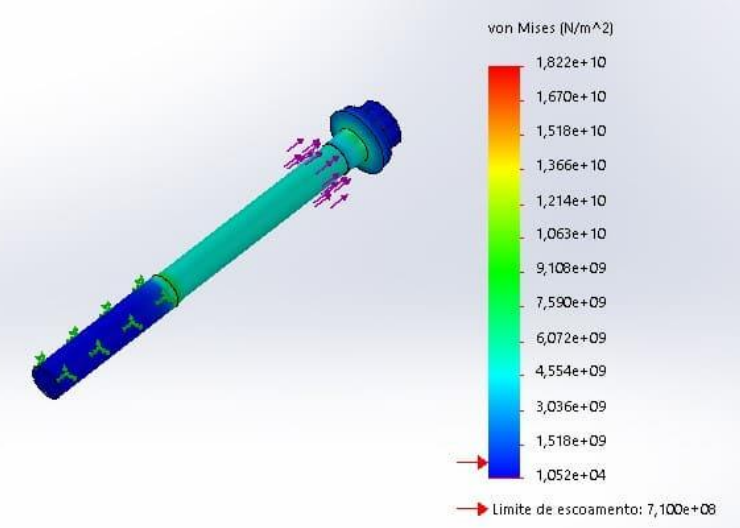

RC: 51573

Disponível em: https://www.nucleodoconhecimento.com.br/engenharia-mecanica/elasticidade-eplasticidade 
Fonte: Autor (2020)

Para o quarto experimento utilizamos o cabeçote do carro Zafira, e, dessa forma, a tensão média encontrada foi de $477 \mathrm{KPa}$, conforme aponta o gráfico 6 , constatandose, então, uma deformação plástica média de $0,87 \mathrm{~mm}$.

Gráfico 6: Parafusos de cabeçote Zafira 2.0

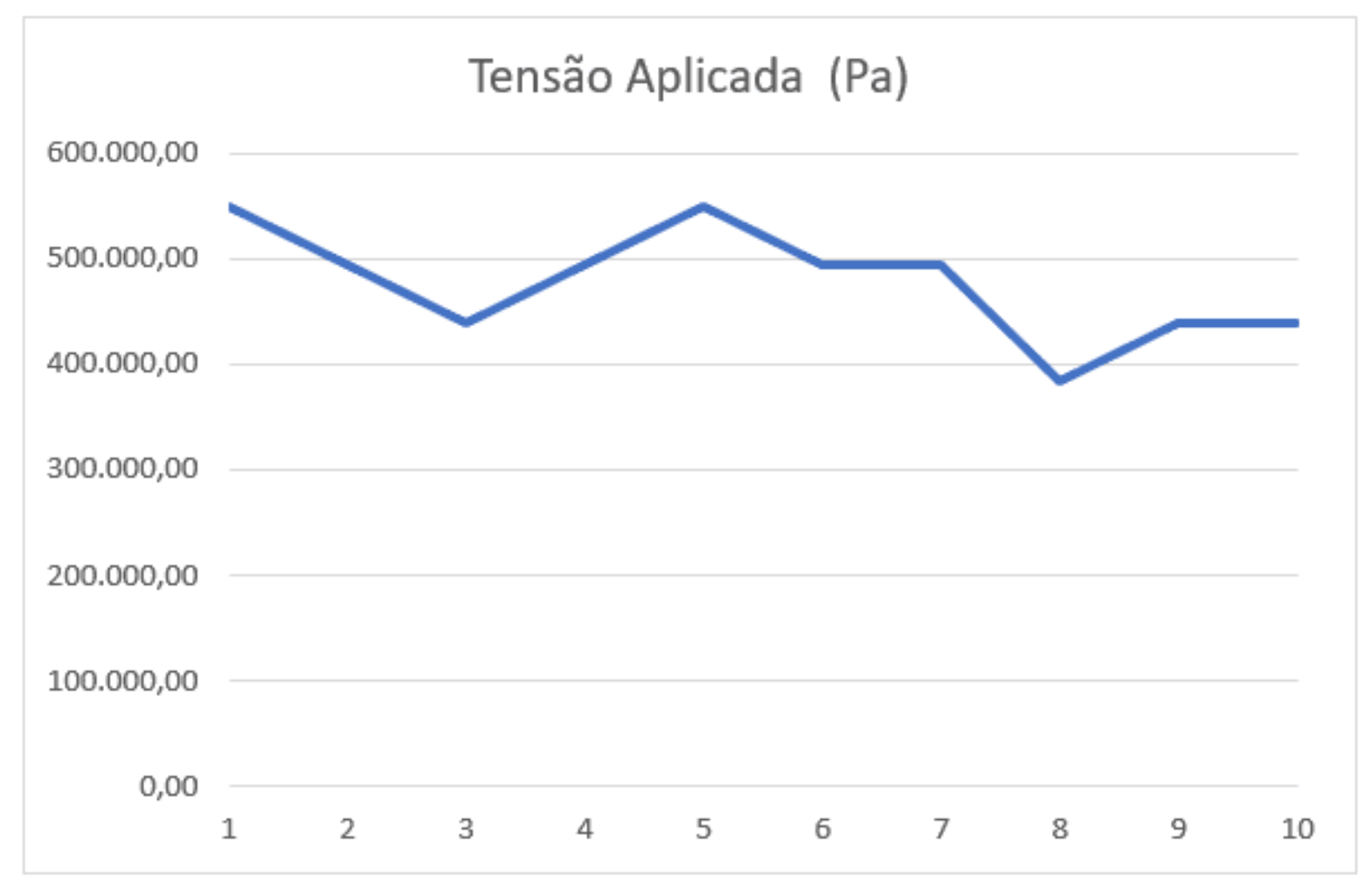

Fonte: Autor (2020)

Disponível em: https://www.nucleodoconhecimento.com.br/engenharia-mecanica/elasticidade-eplasticidade 
Figura 7: Parafuso Zafira - SolidWorks 2019

Nome do modelo:Parafuso zafira 2.0

No me do estudo:Análise estática 1 (-Valor predeterminado-)

Tipo de plotagem: Deformação estática Deformação 1

Escala de distor క̧ão: 6,84693
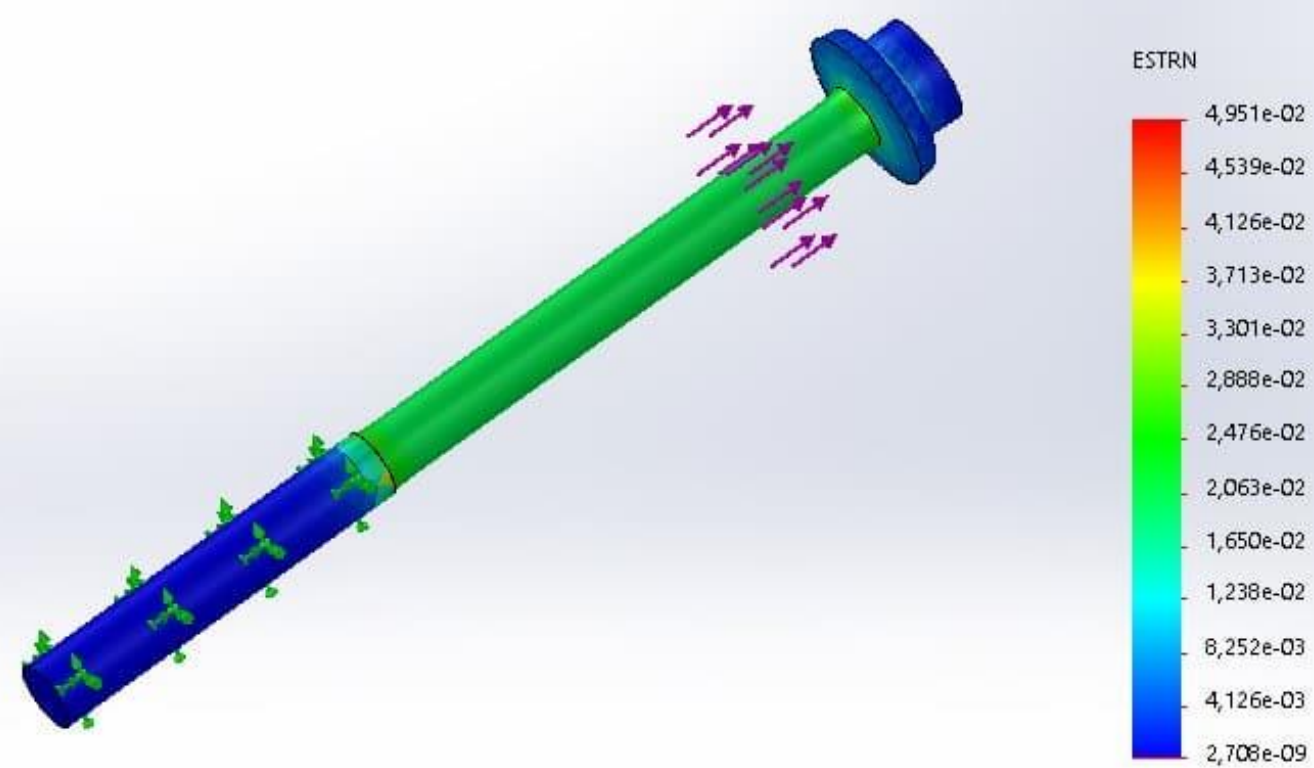

Fonte: Autor (2020)

Observando o quinto e último experimento feito no cabeçote do carro Palio, a tensão média encontrada foi de $667 \mathrm{KPa}$, como ilustra o gráfico 7 , e, assim, obteve-se um deslocamento médio de $0,94 \mathrm{~mm}$.

Disponível em: https://www.nucleodoconhecimento.com.br/engenharia-mecanica/elasticidade-eplasticidade 
Gráfico 7: Parafusos de cabeçote Palio 1.6

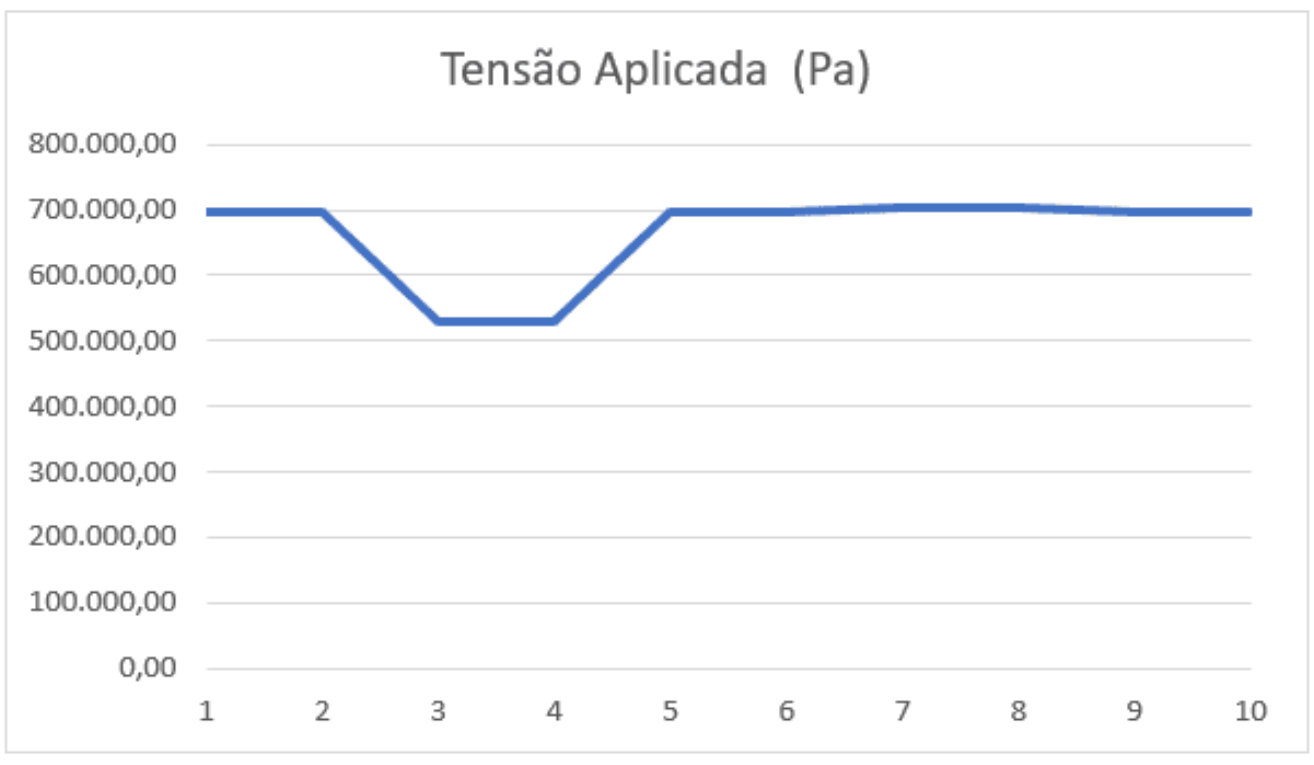

Fonte: Autor (2020)

Figura 8: Parafuso Palio - SolidWorks 2019
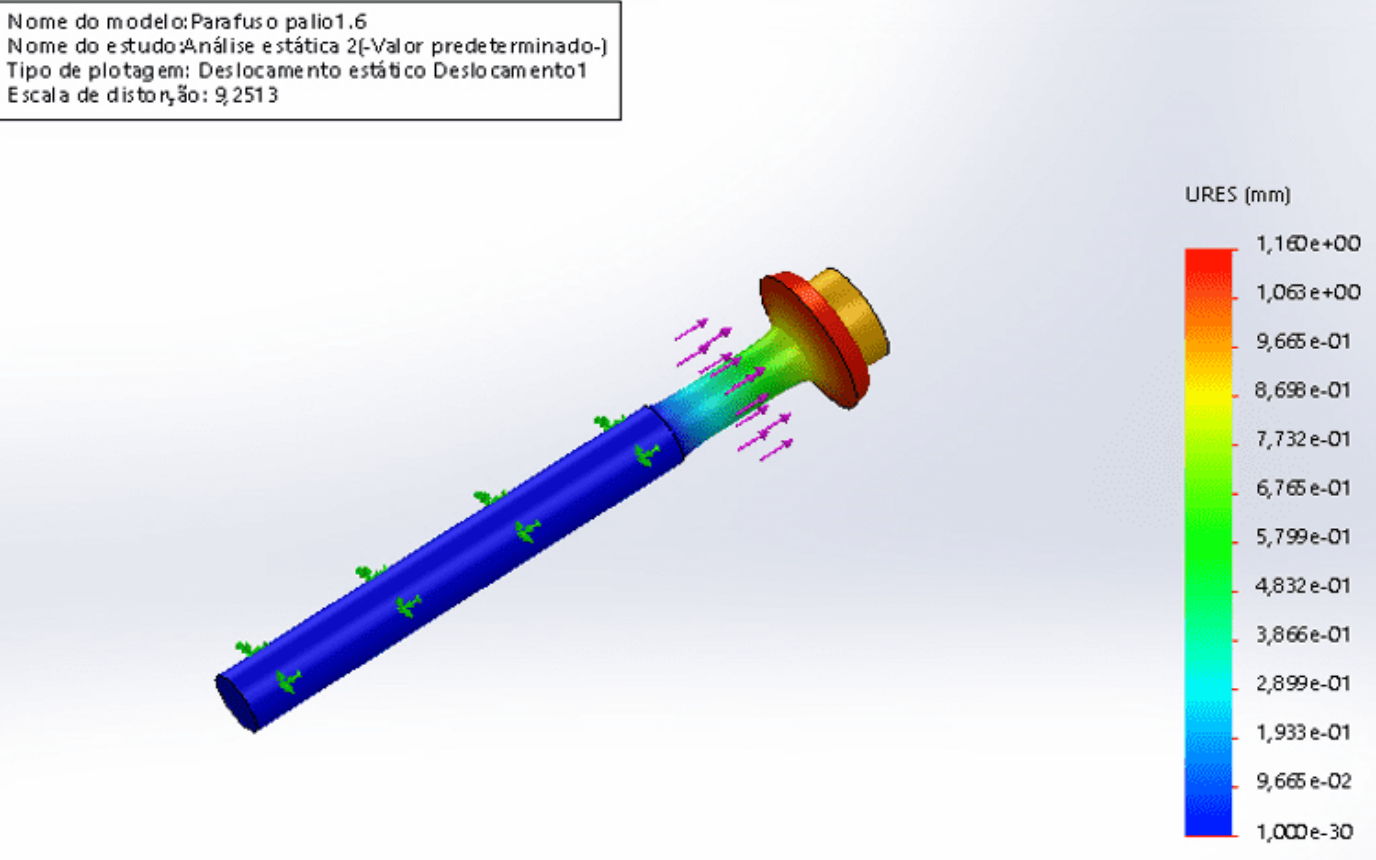

Fonte: Autor (2020)

RC: 51573

Disponível em: https://www.nucleodoconhecimento.com.br/engenharia-mecanica/elasticidade-eplasticidade 


\subsection{ENSAIO DE TRAÇÃO}

Em um ensaio de tração o corpo de prova é subsentido a forças opostas em suas extremidades até sua ruptura (CAMPOS; LAHR, 2004; FIORESE et al, 2015).

\subsection{CORPO DE PROVA}

O corpo de prova é uma amostra do material e tem formato cilíndrico. São utilizadas normas da American Society for Testing and Materials - ASTM, Deutsches Institut für Normung - DIN e da Associação Brasileira de Normas Técnicas-ABNT para uniformização e comparação dos resultados. No ensaio realizado foi utilizada uma amostra de parafuso de cabeçote novo do veículo Pajero 2.8 à diesel.

Figura 9: representação esquemática de um corpo de prova antes de ser submetido ao ensaio de tração

$P=$ forca

So= região de fratura

lo= comprimento útil

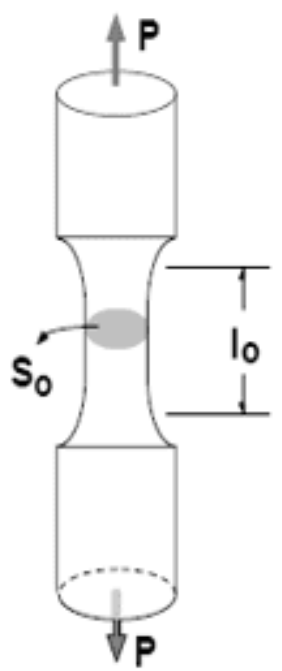

Fonte: Autor (2020)

RC: 51573

Disponível em: https://www.nucleodoconhecimento.com.br/engenharia-mecanica/elasticidade-eplasticidade 
Parâmetros do ensaio de tração

Médias do Corpo de Prova

$d=$ diametro

$\mathrm{lo}=30 \mathrm{~mm}$

$\mathrm{d}=4 \mathrm{~mm}$

Figura 10: Amostra confeccionada do material, parafuso novo cabeçote Pajero 2.8 diesel

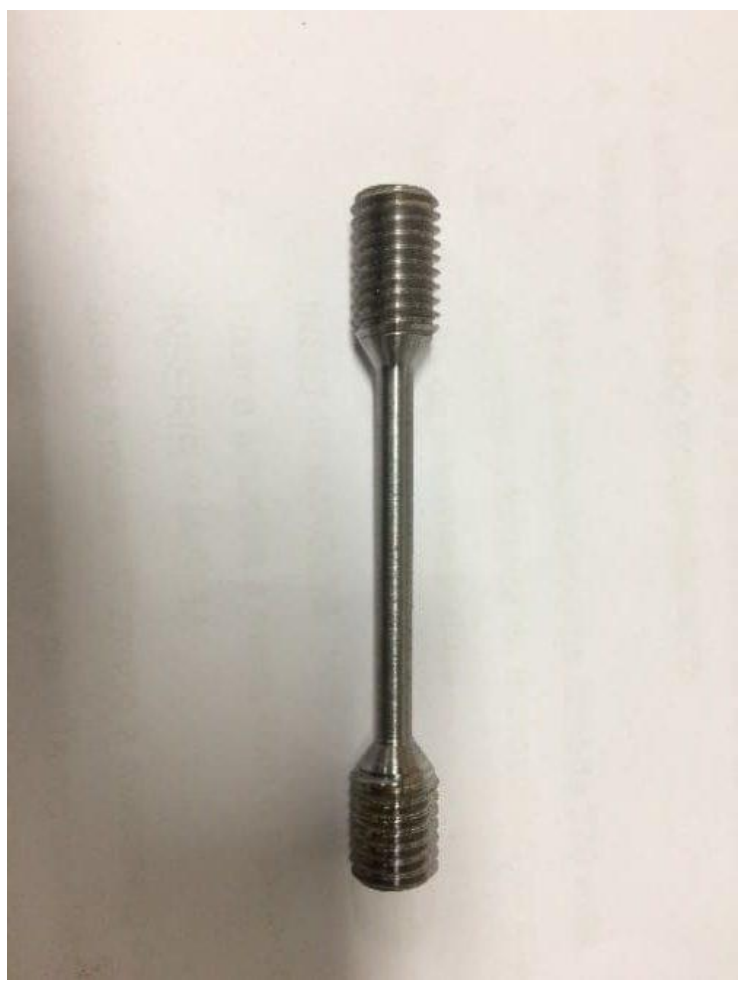

Fonte: Autor (2020) 
Figura 11: Ruptura do material

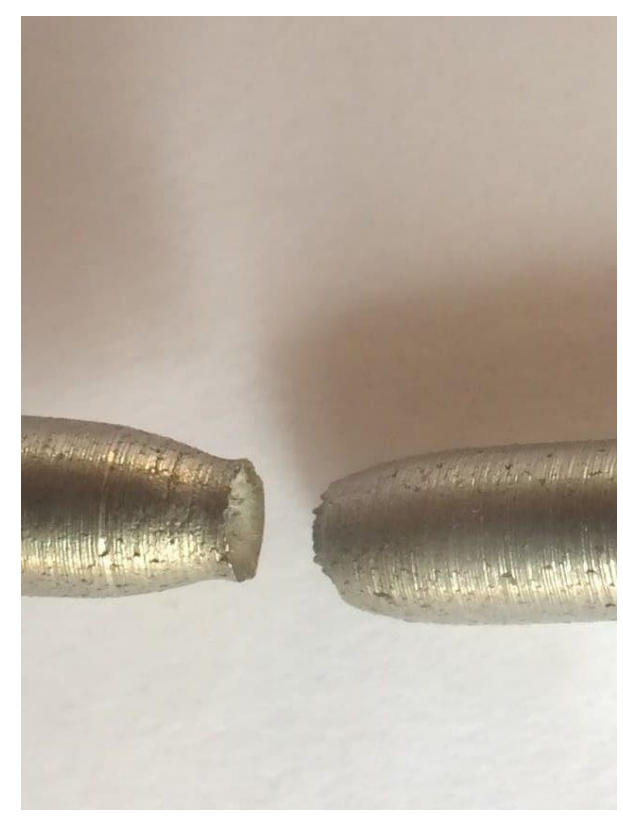

Fonte: Autor (2020)

Figura 12: Gráfico de tensão/deformação carro Pajero 2.8

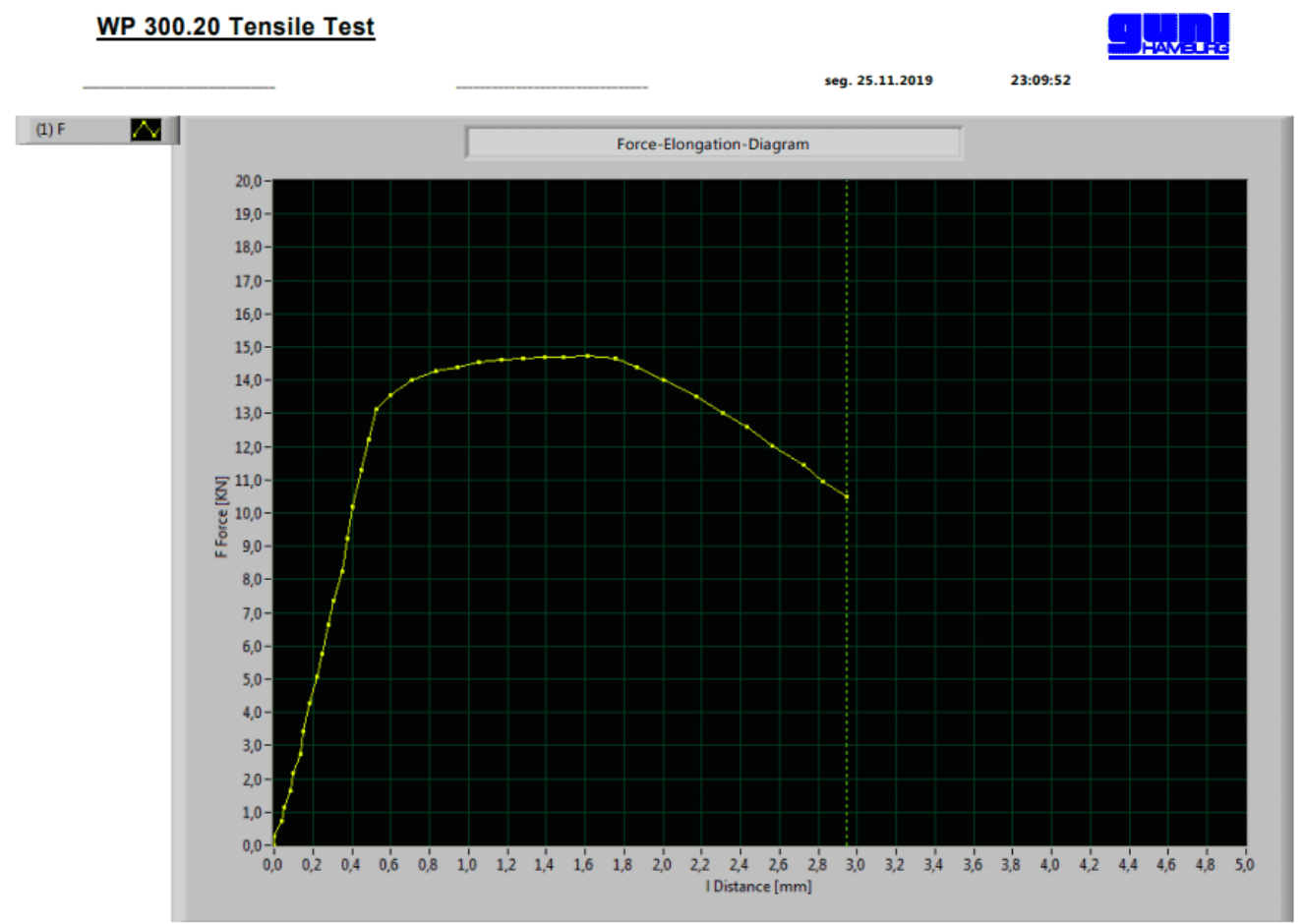

Fonte: Autor (2020)

RC: 51573

Disponível em: https://www.nucleodoconhecimento.com.br/engenharia-mecanica/elasticidade-eplasticidade 
Gráfico 7: Simulação manual

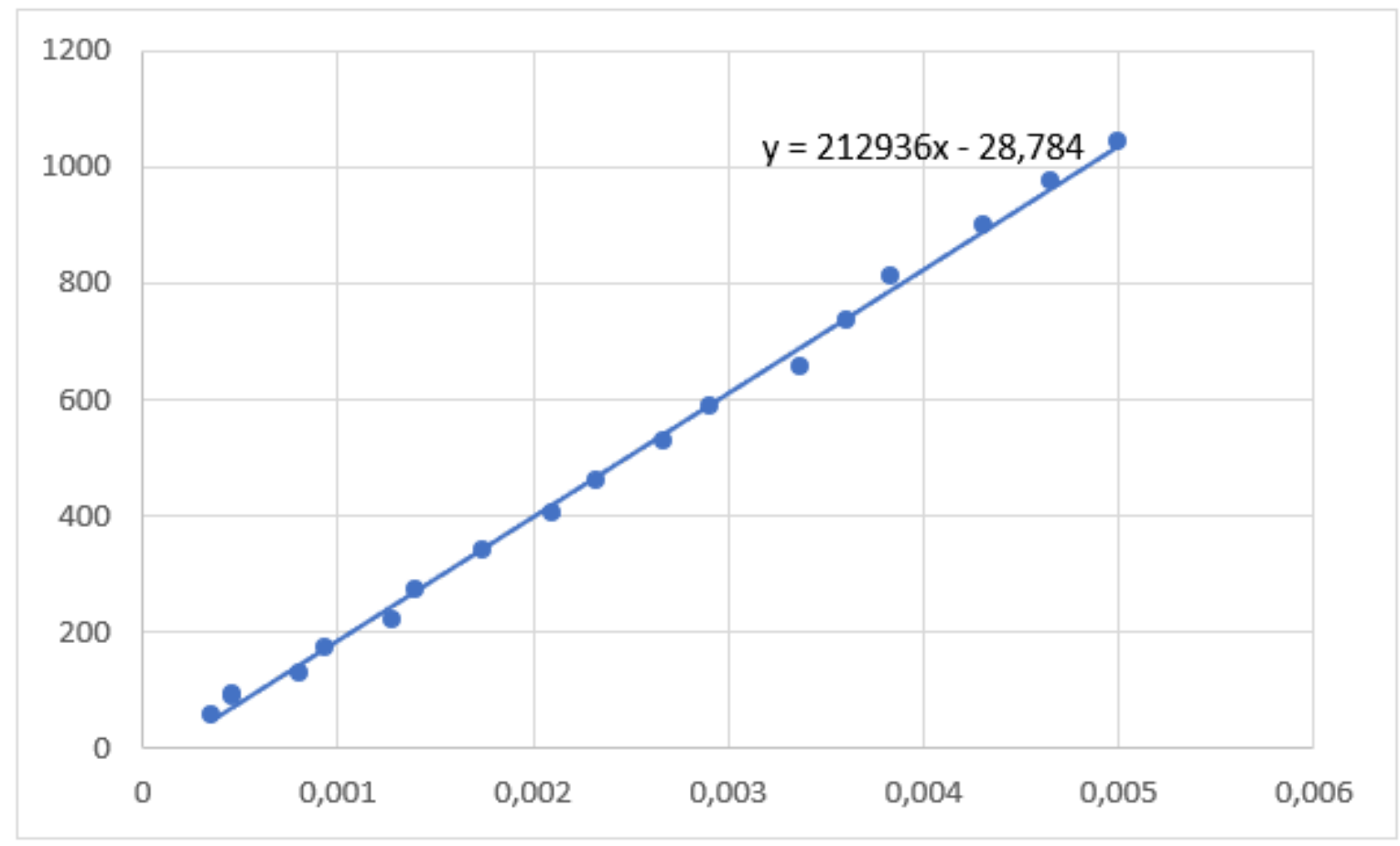

Fonte: Autor (2020)

Os resultados obtidos foram comparados com as tabelas ASTM e SAE para aços de utilização mecânica e apontam que o material tem propriedades relacionadas ao aço AISIN 4340, normatizado conforme a resistência elástica encontrada sendo de aproximadamente 212GPa. O aço AISI 4340 é um material ligado ao cromo e molibdênio, apresenta boa resistência mecânica, usinabilidade média, baixa soldabilidade e alta temperabilidade. Este material frequentemente é empregado em componentes mecânicos, em geral sob a ação de tensões dinâmicas e utilizado para a fabricação de peças na indústria automotiva e na indústria petrolífera e de construção naval (KUPKA, 2009). Este material é classificado como um aço de baixa liga com médio carbono, apresentando alta tenacidade e alta resistência (ARAÚJO MORALES, 2017).

Disponível em: https://www.nucleodoconhecimento.com.br/engenharia-mecanica/elasticidade-eplasticidade 


\section{CONSIDERAÇÕES FINAIS}

A pesquisa buscou ressaltar que as fórmulas utilizadas baseiam-se na Lei de Hooke para o regime elástico por não conhecer dados exatos de cada parafuso, pois as propriedades estruturais dos metais ou materiais são específicas, suas propriedades variam entre os fabricantes e, ainda, devido ao segredo industrial de cada montadora, não conseguimos dados exatos de cada parafuso. Foram utilizadas as propriedades do aço 6150 para parafusos do carro Zafira e o aço 4340 normatizado para os parafusos dos demais carros devido as características apresentadas durante o estudo. Após análise dos dados, foi verificado cada parafuso que apresentou deslocamentos diferentes do real para o software.

Obtemos, a partir dos experimentos realizados, os resultados percentuais do Diferencial Real x SolidWorks do Marea tipo 1 que foi de 1,65\%, do Marea tipo 2 que totalizou $0,79 \%$, da Pajero que foi de $0,68 \%$, do Zafira que somou $1,31 \%$ e do Palio que resultou em $0,16 \%$. Foi realizada a análise dos dados obtidos por meio da simulação manual, software Solidworks2019, ensaio laboratorial, auxílio do Excel e realizou-se uma vasta pesquisa de literatura. Verificou-se que ambos os resultados convergem para uma aproximação matemática entre os métodos computacionais de análise de elementos finitos e o cálculo manual da elasticidade e plasticidade dos parafusos de cabeçote automotivo.

\section{REFERÊNCIAS}

ARAÚJO, T. V. G. P. Sistema Embarcado para Monitoramento de Particulados de Carbono em Emissões de Motores do Ciclo Diesel. 2007. 96f. Dissertação (Mestrado em Engenharia Elétrica) - Universidade Federal de Campina Grande, Campina Grande, 2007.

BLOG LUZ. Materiais. Disponível em: http://materiais.gelsonluz.com. Acesso em: 18 nov. 2019. 
BLOG. O Mecânico. Disponível em: http://omecanico.com.br. Acesso em: 19 nov. 2019.

BLOG. Roman, Aços. Disponível em: http://aco.com.br/. Acesso em: 19 nov. 2019.

CAMPOS, C. I de.; LAHR, F. A. R. Estudo comparativo dos resultados de ensaio de tração perpendicular para MDF produzido em laboratório com fibras de pinus e de eucalipto utilizando uréia-formaldeído. Matéria, v. 9, n. 1, p. 32-42, 2004.

COURTES, R. A. et al. O comportamento mecânico dos parafusos de fixação de cabeçote dos motores VW AP quando reutilizados. In: Salão Internacional de Ensino, Pesquisa e Extensão, 2017.

FERNANDEZ, B. O. Considerações sobre outros empregos do sensor de detonação para o controle eletrônico de motores ciclo Otto utilizando análise espacial. 2006. 146f. Dissertação (Mestrado em Engenharia) - Universidade de São Paulo, São Carlos, 2006.

FIORESE, D. A. et al. Desempenho de três tratores agrícolas em ensaios de tração. Journal of Neotropical Agriculture, v. 2, n. 2, p. 68-76, 2015.

GARCIA, R. Conceitos gerais sobre torque e processos de torque - Parte I. São Paulo: Revista do Parafuso, 2008.

LA CAVA, C. A. P. L. et al. Modelagem de um dispositivo de pré-carga com memória de forma para juntas flangeadas. In: Congresso Nacional de Engenharia Mecânica (CD-ROM), 2000.

MONTEIRO, C. A. M. Medição indireta de torque e velocidade angular de motor de corrente contínua sem escovas. 2016. 150f. Dissertação (Mestrado em Engenharia Mecânica) - Universidade Federal de Santa Catarina, Florianópolis, 2016.

NORTON, R. Projeto de máquinas: uma abordagem integrada. 4aㅗ ed. Porto Alegre: Bookman, 2013. 
PORTO, I. G. Interferências tribológicas na união do cabeçote associados à vedação e seus efeitos no processo de aperto da junta aparafusada. 2017. $69 \mathrm{f}$. Dissertação (Mestrado em Engenharia Automotiva) - Universidade de São Paulo, São Paulo, 2017.

SCHWONBACH, E. R. et al. Pré-carga de parafuso com tratamento de superfície Diamond-like carbon: prevenção do desaperto. RGO, v. 56, n. 1, p. 93-96, 2008.

SILVEIRA, F. L. da. Máquinas térmicas à combustão interna de Otto e de Diesel. In: Instituto de Física da Universidade Federal do Rio Grande do Sul, 2008.

SOLIDWORKS 3D design de Software. Versão 2016 x64 Edition SP0.

Enviado: Janeiro, 2020.

Aprovado: Junho, 2020. 